OPEN ACCESS

Edited by:

Lu Cai,

University of Louisville, United States

Reviewed by:

Mahnaz Hosseini-Bensenjan,

Shiraz University of Medical Sciences,

Wiraphol Phimarn,

Mahasarakham University, Thailand

${ }^{*}$ Correspondence:

Yuxia Ma

mayuxia@hebmu.edu.cn

${ }^{\text {t}}$ These authors have contributed equally to this work and share

first authorship

Specialty section:

This article was submitted to Cardiovascular Endocrinology,

a section of the journal

Frontiers in Endocrinology

Received: 23 December 2021

Accepted: 26 January 2022

Published: 04 March 2022

Citation:

Sun Y, Ren J, Zhu S, Zhang Z,

Guo Z, An J, Yin B and Ma Y

(2022) The Effects of Sesamin

Supplementation on Obesity, Blood

Pressure, and Lipid Profile: A

Systematic Review and Meta-Analysis

of Randomized Controlled Trials.

Front. Endocrinol. 13:842152.

doi: 10.3389/fendo.2022.842152

\section{The Effects of Sesamin} Supplementation on Obesity, Blood Pressure, and Lipid Profile: A Systematic Review and Meta-Analysis of Randomized Controlled Trials

Yiting Sun ${ }^{1+}$, Jingyi Ren ${ }^{2+}$, Siqi Zhu ${ }^{3}$, Zhenao Zhang ${ }^{3}$, Zihao Guo ${ }^{3}$, Jiaqi $A n^{1}$, Bowen Yin $^{2}$ and Yuxia $\mathrm{Ma}^{2 *}$

\footnotetext{
1 Undergraduate of College of Basic Medicine, Hebei Medical University, Shijiazhuang, China, ${ }^{2}$ Department of Nutrition and Food Hygiene, School of Public Health, Hebei Medical University, Hebei Province Key Laboratory of Environment and Human Health, Shijiazhuang, China, ${ }^{3}$ Undergraduate of College of Public Health, Hebei Medical University, Shijiazhuang, China
}

Aims: Sesamin, the main lignin constituent of sesame, plays a pivotal role in regulating physical state. Some studies have evidenced that the supplementation of sesamin may decrease cardiovascular disease risk. The goal of this systematic review was to summarize evidence of the effects of sesamin supplementation on obesity, blood pressure, and lipid profile in humans by performing a meta-analysis of randomized controlled trials.

Data Synthesis: Five databases (PubMed, Cochrane Library, EMBASE, Web of Science, and Scopus) were searched electronically from inception to July 2021 to identify randomized controlled trials that assessed the impact of sesamin on obesity, blood pressure, and lipid profile. Weighted mean difference (WMD) and standard deviation (SD) were used to present the major outcomes.

Conclusions: Seven trials ( $n=212$ participants) were included in the overall analysis. Results showed that sesamin supplementation caused a great reduction in TC (WMD: $-10.893 \mathrm{mg} / \mathrm{dl}, 95 \% \mathrm{Cl}:-19.745$ to $-2.041, \mathrm{p}=0.016)$, LDL-c (WMD: $-8.429 \mathrm{mg} / \mathrm{dl}, 95 \%$ $\mathrm{Cl}:-16.086$ to $-0.771, \mathrm{p}=0.031)$, and SBP (WMD: $-3.662 \mathrm{mmHg}, 95 \% \mathrm{Cl}:-6.220$ to $-1.105, p=0.005)$, whereas it had no effect on HDL-c, TG, DBP, or weight. Subgroup analysis showed that duration, parallel design, and unhealthy status can affect TC, LDL-C, and SBP evidently. We did not discover a strong link between indicators' changes and duration of supplementation. Sesamin can be used as an obtainable dietary supplement to improve blood pressure and blood lipids, and further as a health product to prevent cardiovascular diseases.

Keywords: sesamin, obesity, blood pressure, lipid profile, meta-analysis 


\section{INTRODUCTION}

At the global level, the highest per capita cardiovascular disease (CVD) burden remains in the countries of Eastern Europe and Central Asia (1). Several published articles have mentioned that potentially modifiable risk factors, such as high blood pressure (BP), raised serum lipids, and obesity may play key roles in promoting the pathogenesis of CVDs (2-4). Blood profile levels are good indicators of cardiovascular risk and good predictors of coronary disease outcome (5). Dyslipidemia, defined as elevated levels of triglycerides and cholesterol (particularly LDL-c) and reduced levels of HDL-c, has been introduced as a strong risk factor for CVD $(6,7)$. High blood lipid levels can result in serious damage to systemic blood vessels and organs $(8,9)$. Several significant associations have been shown between CVD burden and circulatilng levels of LDL-c, HDL-c, and triglycerides $(10,11)$. Hypertension (systolic blood pressure $\geq 140 \mathrm{mmHg}$ or diastolic blood pressure $\geq 90 \mathrm{mmHg}$ ) (12) and CVDs are inseparable, too.

Sesamin, which constitutes $1.5 \%$ of the weight of sesame seed (13), has been consumed as a health natural supplement. This nutrient is also present in several plants distributed in different genera, including camellia, magnolia, piper, sesamum, and virola (14). It has traditionally been believed to have health benefits in some East Asian countries for many years. In the recent decades, it has been shown that sesamin exhibits several physiological actions in animals, such as antiobesity, antihypertensive, and serum lipid-lowering effects (15-17). The animal experiment showed that sesamin has been used to decrease blood lipids and blood glucose levels in the aorta of rats with metabolic syndrome (18). Several animal studies have also confirmed that the supplementation of sesame seeds or sesamin could decrease cholesterol levels $(19,20)$.

Hirata et al. (21) have experimented with sesamin on human subjects, and the results were surprising. TC and LDL-c were significantly lower in the sesamin-treated group. Similarly, the results obtained by Mohammadshahi (22) also had an effect on TC and LDL-c. Up to now, randomized controlled trials (RCTs) have not reached a consistent conclusion about the effect of sesamin on blood pressure and lipid profile $(23,24)$.

Given the evidence that sesamin is related to a decreased risk of CVD, we carried out a systematic review and meta-analysis, which aims at determining whether sesamin intake has the potential to be used as an adjuvant therapy for persons who have cardiovascular disease.

\section{MATERIALS AND METHODS}

This study was executed based on the Preferred Reporting Items for Systematic Reviews and Meta-Analyses (PRISMA) guidelines (25) and registered in the International Prospective Register of

Abbreviations: CI, confidence interval; TC, total cholesterol; TG, triglyceride; HDL-c, high-density lipoprotein-cholesterol; LDL-c, low-density lipoproteincholesterol; RCT, randomized controlled trial; SD, standard deviations; SE, standard error; WMD, weighted mean difference; CVD, cardiovascular diseases; PRISMA, Preferred Reporting Items for Systematic Reviews and Meta-Analysis.
Systematic Reviews (PROSPERO) database under the registration number CRD42021271145.

\subsection{Search Strategy}

Systematic literature retrieval was performed in the PubMed, SCOPUS, Cochrane Library, Embase, and ISI Web of Science databases from inception to July 2021 to determine a randomized controlled trial evaluating the effects of sesamin on obesity, blood pressure, and lipid profile. Medical subject heading terms (Mesh) were used: ("sesame" OR "sesamin" OR "sesamum") AND ("Blood Pressure" OR "Hypertension" OR "High Blood Pressure") AND ("HDL" OR "LDL" OR "Triglyceride" OR "Total cholesterol") AND ("BMI" OR "Weight") (Supplementary Material, which illustrates the search strategies). Then, the retrieved manuscripts were imported into EndNote software (version X9) to remove the duplicates. The inclusion and exclusion criteria are listed in Table 1. Two authors (YS and JR) independently and cooperatively determined suitable manuscripts for inclusion. Disagreements were discussed by the third author (SZ).

\subsection{Data Extraction}

Based on the pre-designed table, the important report data are listed as the following: publication information (first author's last name, the year published, study location), the details of the clinical trial (study design, intervention duration), the participants' characteristics (sample size, age, gender, health status), and all reported outcomes of interest. Standard deviation (SD), belonging to the category of descriptive statistics, was the experimental index to be captured. When SE was reported, we use the formula between SD and SEM (SD = SEM $\times$ sqrt (n); $\mathrm{n}=$ number of participants) to convert.

\subsection{Assessment of Quality}

Trials were assessed for bias risk using the Cochrane Bias Risk Tool (26) which includes sequence generation, allocation concealment, blinding, blinding of outcome assessment, incomplete outcome data, selective outcome reporting, and other bias. We ranked for "low", "high", or "unclear" risk of bias.

\subsection{Quantitative Data Synthesis}

All the analyses were performed using STATA version 11. Weighted mean difference (WMD), SD, and 95\% CI were used as the effective measures for SBP, DBP, HDL-c, LDL-c, TG, TC, and weight. The net changes in them were equal to the postintervention values minus the baseline values. The SD of the mean difference was calculated by the following formula:

$$
\begin{aligned}
\mathrm{SD}= & \text { square root }\left[\left(\mathrm{SD}_{\text {pre-treatment }}\right)^{2}+\left(\mathrm{SD}_{\text {post-treatment }}\right)^{2}-(2 \mathrm{R}\right. \\
& \left.\left.\times \mathrm{SD}_{\text {pre-treatmen }} \times \mathrm{SD}_{\text {post-treatment }}\right)\right]
\end{aligned}
$$

assuming a correlation coefficient $(\mathrm{R})=0.5$ for both the pre-test/ post-test (parallel groups) and the crossover designed studies. The heterogeneity index $\mathrm{I}^{2}$ is used for quantitative analysis of heterogeneity, which ranges from $0 \%$ to $100 \%$. There is no heterogeneity at $0 \%$. The greater the $\mathrm{I}^{2}$ value, the greater the heterogeneity. There was no statistical heterogeneity 
TABLE 1 | PICOS criteria for inclusion of studies.

\begin{tabular}{|c|c|}
\hline Parameter & Description \\
\hline Population & Adult participants (healthy/unhealthy) \\
\hline \multirow[t]{2}{*}{ Intervention } & I Sesamin administered for $\geq 2$ weeks \\
\hline & II Sesamin dosage is clearly indicated \\
\hline Comparator & Placebo \\
\hline Outcomes & $\begin{array}{l}\text { Outcomes regarding at least one of the following markers: } \\
\text { cholesterol, total cholesterol, high-density lipoprotein, low-density } \\
\text { lipoprotein, triglycerides, triacylglycerol, VLDL, BMl, weight, blood } \\
\text { pressure, diastolic blood pressure, systolic blood pressure }\end{array}$ \\
\hline $\begin{array}{l}\text { Study } \\
\text { design }\end{array}$ & $\begin{array}{l}\text { Randomized placebo-controlled clinical trial with a cross-over or } \\
\text { parallel design }\end{array}$ \\
\hline
\end{tabular}

$\left(\mathrm{I}^{2}<50 \%\right)$ among the results of each study, and a fixed-effect model was used. If there was statistical heterogeneity $\left(\mathrm{I}^{2} \geq 50 \%\right)$ among the results, the random-effect model was used.

\subsection{Meta-Regression Analysis}

Meta-regression analysis was performed to calculate the duration-effect relationship between WMD and duration to explore potential explanations for heterogeneity.

\subsection{Subgroup Analysis}

We also conducted subgroup analysis studies including treatment duration ( $<42$ days or $\geq 42$ days), study design (crossover or parallel), and participants' health status (healthy or unhealthy). To evaluate the influence of individual study on the pooled-effect size, sensitivity analysis (leave-one-out) was conducted and $\mathrm{p}<0.05$ was considered as statistically significant.

\subsection{Publication Bias}

Begg's rank correlation and Egger's weighted regression statistics were used to evaluate potential publication bias $(27,28)$. $p$ values less than 0.1 were considered statistically significant.

\section{RESULTS}

\subsection{Flow and Characteristics of the Included Study}

The initial search identified 527 papers for screening, of which 121 were removed because of duplication (Figure 1). After title and abstract screening, 365 records were excluded due to irrelevance to the inclusion criteria. The full texts of the remaining 41 articles were further screened, after which 34 studies were excluded for the following reasons: lack of sufficient information on the outcomes of interest $(n=6)$; the dosage of sesamin was not specified $(n=17)$; study not designed as an $\operatorname{RCT}(n=6)$; and article published as meta-analysis or review $(\mathrm{n}=5)$. Finally, 7 articles $(15,21-24,29,30)$ with 212 arms were enrolled in the present meta-analysis. The PRISMA flowchart of the study is shown in the following.

\subsection{Characteristics and Quality of Included Studies}

Characteristics of the included studies are shown in Table 2. Each of the included articles stated sesamin dosage, and four of the

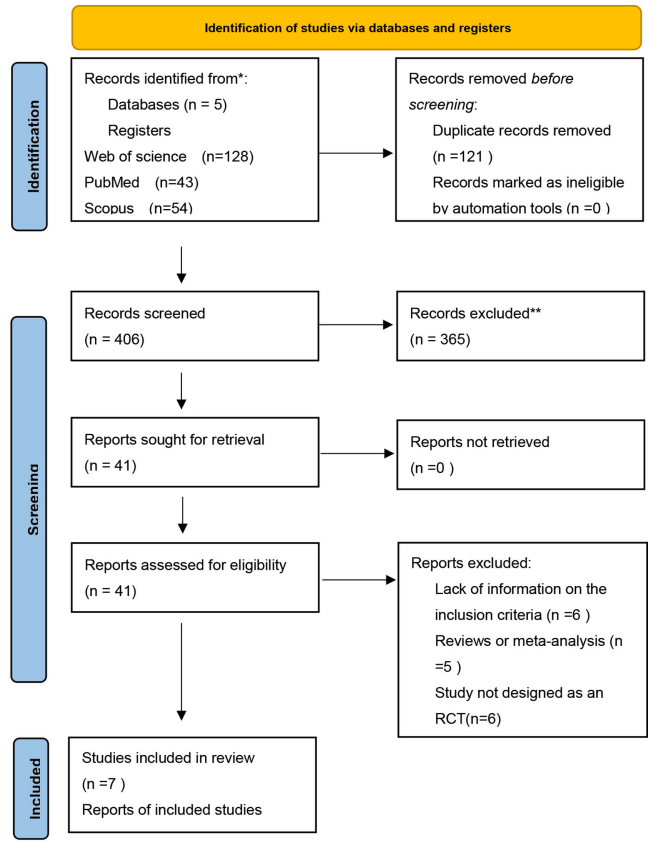

FIGURE 1 | The PRISMA flowchart.

studies had dosages less than $200 \mathrm{mg}$ /day. Four studies were on obesity, four studies were on BP, and five studies were on lipid profile. Included studies have been published between 1996 and 2016 and were conducted in 5 different areas: Japan, Taiwan, Australia, Thailand, and Iran. A total of 212 participants were enrolled in studies, and intervention duration ranged from 28 to 60 days. Four studies had a parallel design and three studies had a crossover design. Six trials were conducted in unhealthy individuals, and one trial was carried through healthy individuals.

\subsection{Findings From Meta-Analysis}

Meta-analysis showed that sesamin supplementation caused a great reduction in TC (WMD: $-10.893 \mathrm{mg} / \mathrm{dl}, 95 \% \mathrm{CI}:-19.745$ to $-2.041, \mathrm{p}=0.016)$, LDL-c (WMD: $-8.429 \mathrm{mg} / \mathrm{dl}$, 95\% CI: -16.086 to $-0.771, \mathrm{p}=0.031$ ), and SBP (WMD: $-3.662 \mathrm{mmHg}$, 95\% CI: -6.220 to $-1.105, \mathrm{p}=0.005$ ) (Figure 2).

\subsubsection{Effect of Sesamin Supplementation on Obesity Levels}

Levels of obesity were reported in four of the included studies, including 145 participants. Sesamin ingestion showed a nonsignificant effect on mean body weight (WMD: $-0.223,95 \%$ CI: -3.766 to $3.321 ; \mathrm{p}=0.902)$ compared with control, without heterogeneity among the studies $\left(\mathrm{I}^{2}=0.0 \%, \mathrm{p}=0.976\right)$.

\subsubsection{Effect of Sesamin Supplementation on BP Levels}

The effect of sesamin on $\mathrm{BP}$ was reported in four treatments with 132 participants. Sesamin intake did significantly affect SBP (WMD: $-3.662 \mathrm{mmHg}, 95 \% \mathrm{CI}:-6.220$ to $-1.105, \mathrm{p}=0.005$; $\left.\mathrm{I}^{2}=20.8 \%\right)$. However, the pooled result using a random-effect 


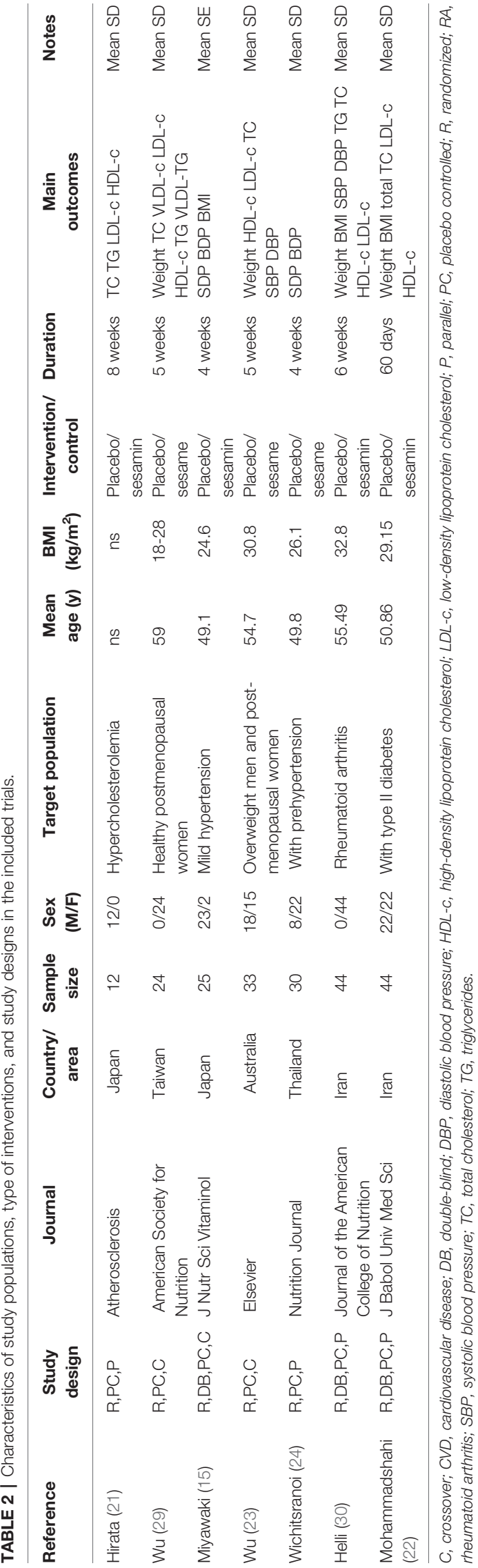

model showed a reduction in DBP ( WMD $=-2.304 \mathrm{mmHg}$, 95\% CI: -5.596 to $0.988, \mathrm{p}=0.170$ ) with sesamin intake. A high heterogeneity was also detected in DBP $\left(\mathrm{I}^{2}=62.4 \%\right)$.

\subsubsection{Effect of Sesamin Supplementation on Lipid Profile Levels}

Five trials with 157 participants measured the effect of sesamin supplementation on TC and LDL-c. Moreover, the results of TC $(\mathrm{WMD}=-10.893 \mathrm{mg} / \mathrm{dl}, 95 \% \mathrm{CI}:-19.745$ to $-2.041, \mathrm{p}=0.016$; $\left.\mathrm{I}^{2}=49.8 \%\right)$ and LDL-c (WMD $=-8.429 \mathrm{mg} / \mathrm{dl}, 95 \%$ CI: -16.086 to $-0.771, \mathrm{p}=0.031 ; \mathrm{I}^{2}=53.3 \%$ ) are detected following sesamin supplementation. With random-effect models, the $\mathrm{I}^{2}$ value of LDL-c was $53.3 \%$, and the related $\mathrm{p}$ value was 0.073 .

Four trials with 145 participants consuming sesamin affected HDL-c and TG. HDL-c (WMD $=1.644 \mathrm{mg} / \mathrm{dl}, 95 \% \mathrm{CI}:-1.560$ to $\left.4.848, \mathrm{p}=0.314 ; \mathrm{I}^{2}=0.0 \%\right)$ and $\mathrm{TG}(\mathrm{WMD}=-2.034 \mathrm{mg} / \mathrm{dl}, 95 \%$ CI: -16.298 to $\left.12.229, \mathrm{p}=0.780 ; \mathrm{I}^{2}=0 \%\right)$ concentrations did not alter significantly following sesamin intake.

\subsection{Risk-of-Bias Assessment}

The quality of studies was evaluated by using the Cochrane collaboration's risk-of-bias assessment tool. Random sequence generation, allocation concealment, and blinding of outcome assessment of participants were low risk of bias in all included studies. Only one trial had a high risk of bias due to the incomplete outcome. Details of the quality of studies are shown in Table 3.

\subsection{Meta-Regression Analysis}

Results of meta-regression suggested no clear relationship between the duration and biomarkers we conducted (TC: coefficient $=0.377, \mathrm{p}=0.671 ;$ LDL-c: coefficient $=0.395, \mathrm{p}=$ 0.686; HDL-c: coefficient $=1.043, \mathrm{p}=0.988$; TG: coefficient $=$ 2.039, $\mathrm{p}=0.806 ;$ SBP: coefficient $=1.414, \mathrm{p}=0.921 ; \mathrm{DBP}$ : coefficient $=1.575, \mathrm{p}=0.897$; weight: coefficient $=0.987, \mathrm{p}=$ 0.996; Figure 3).

\subsection{Subgroup Analysis}

Subgroup analyses showed no significant differences in the effect of sesamin on HDL-c, TG concentrations, and weight between subgroups, which are stratified by intervention duration ( $\geq 42$ days vs. $<42$ days), study design (parallel vs. crossover), and health status (healthy vs. unhealthy) (Table 4). It indicated that reduction was greater in trials conducted with longer duration, as for TC (WMD $=-21.363 \mathrm{mg} / \mathrm{dl}, 95 \% \mathrm{CI}:-34.090$ to $\left.-8.636, \mathrm{p}=0.001 ; \mathrm{I}^{2}=0.0 \%\right)$ and LDL-c $(\mathrm{WMD}=-14.434 \mathrm{mg} / \mathrm{dl}$, 95\% CI: -24.929 to $\left.-3.939, \mathrm{p}=0.007 ; \mathrm{I}^{2}=55.2 \%\right)$. However, the reduction was more remarkable in participants with shorter duration ( $<42$ days), as for SBP (WMD $=-3.824 \mathrm{mmHg}$, 95\% CI: -6.588 to $\left.-1.060, \mathrm{p}=0.007 ; \mathrm{I}^{2}=45.9 \%\right)$. In addition, the trials conducted in unhealthy participants showed a remarkable reduction in TC $(\mathrm{WMD}=-21.363 \mathrm{mg} / \mathrm{dl}, 95 \% \mathrm{CI}:-34.09$ to $\left.-8.636, \mathrm{p}=0.001 ; \mathrm{I}^{2}=0.0 \%\right)$, LDL-c $(\mathrm{WMD}=-14.434 \mathrm{mg} / \mathrm{dl}$, 95\% CI: -24.929 to $\left.-3.939, \mathrm{p}=0.007 ; \mathrm{I}^{2}=55.2 \%\right)$, SBP (WMD = $-4.490 \mathrm{mmHg}, 95 \% \mathrm{CI}:-7.315$ to $\left.-1.666, \mathrm{p}=0.002 ; \mathrm{I}^{2}=0.0 \%\right)$, and DBP (WMD $=-3.542 \mathrm{mmHg}$, 95\% CI: -6.873 to $-0.210, \mathrm{p}=0.037$; $\left.I^{2}=46.0 \%\right)$. Subgroup analysis also suggested that trials with a 

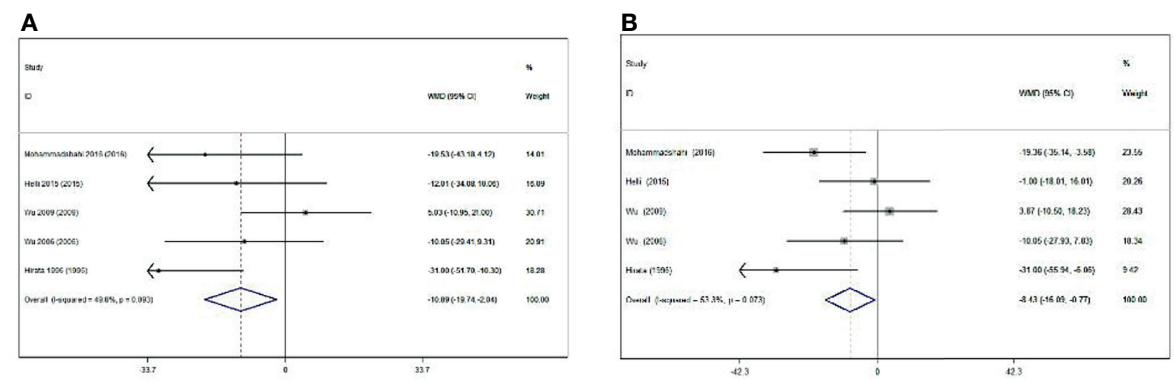

C

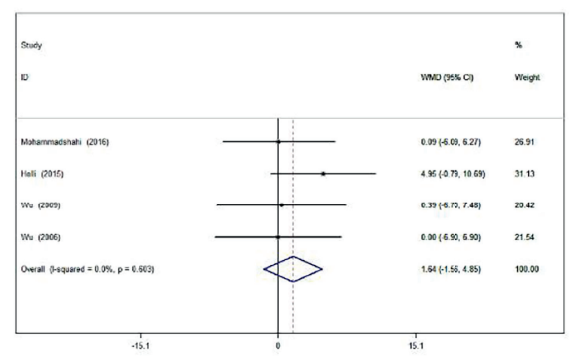

D

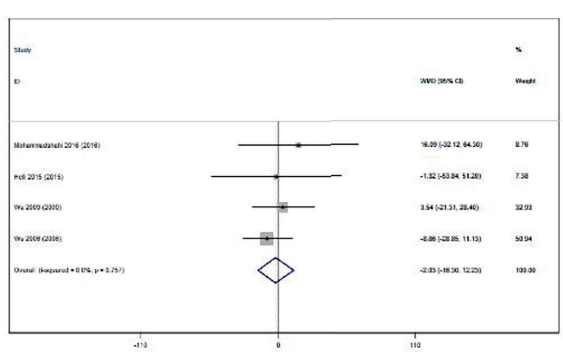

E

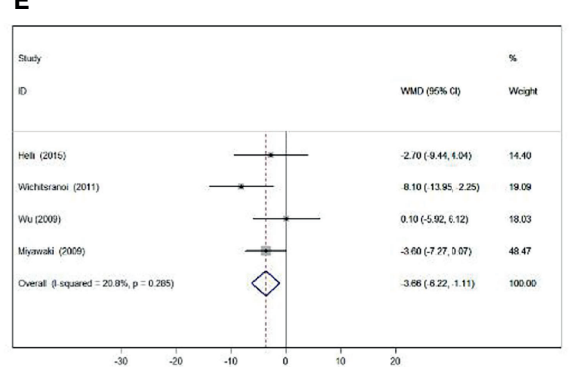

$\mathbf{F}$

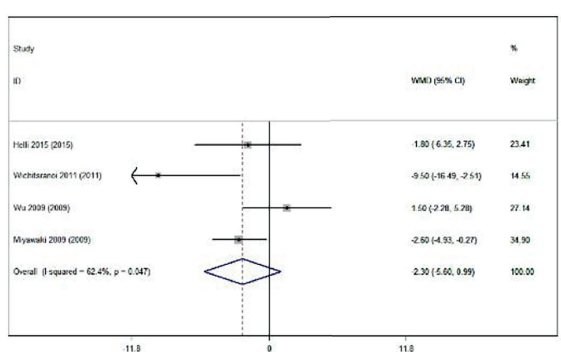

G

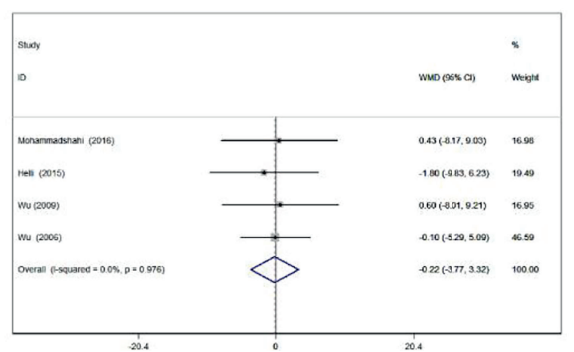

FIGURE 2 | Forest plot of the effect of sesamin supplementation on TC (A), LDL-C (B), HDL-c (C), TG (D), SBP (E), DBP (F), and weight (G). 
TABLE 3 | Assessment of risk of bias in studies included in the meta-analysis.

\begin{tabular}{|c|c|c|c|c|c|c|c|}
\hline & $\begin{array}{c}\text { Random sequence } \\
\text { generation }\end{array}$ & $\begin{array}{c}\text { Allocation } \\
\text { concealment }\end{array}$ & $\begin{array}{l}\text { Blinding of } \\
\text { participants }\end{array}$ & $\begin{array}{c}\text { Blinding of outcome } \\
\text { assessment }\end{array}$ & $\begin{array}{c}\text { Free of incomplete } \\
\text { outcome }\end{array}$ & $\begin{array}{l}\text { Free of selective } \\
\text { reporting }\end{array}$ & $\begin{array}{c}\text { Other } \\
\text { bias }\end{array}$ \\
\hline Hirata (21) & $\mathrm{L}$ & $\mathrm{L}$ & $U$ & $\mathrm{~L}$ & $\mathrm{H}$ & $\mathrm{L}$ & $U$ \\
\hline Wu (29) & $\mathrm{L}$ & $\mathrm{L}$ & $U$ & $\mathrm{~L}$ & $\mathrm{~L}$ & $\mathrm{~L}$ & $\mathrm{~L}$ \\
\hline Miyawaki (15) & $\mathrm{L}$ & $\mathrm{L}$ & $\mathrm{L}$ & $\mathrm{L}$ & $\mathrm{L}$ & $\mathrm{L}$ & $U$ \\
\hline Wu (23) & $\mathrm{L}$ & $\mathrm{L}$ & $L$ & $\mathrm{~L}$ & $U$ & $\mathrm{~L}$ & U \\
\hline Wichitsranoi (24) & $\mathrm{L}$ & $\mathrm{L}$ & $L$ & $\mathrm{~L}$ & $\mathrm{~L}$ & $\mathrm{~L}$ & $U$ \\
\hline Helli (30) & $\mathrm{L}$ & $\mathrm{L}$ & $\mathrm{L}$ & $\mathrm{L}$ & $\mathrm{L}$ & $U$ & $L$ \\
\hline Mohammadshahi (22) & $\mathrm{L}$ & $\mathrm{L}$ & $L$ & $\mathrm{~L}$ & $\mathrm{~L}$ & $\mathrm{~L}$ & $L$ \\
\hline
\end{tabular}

$L$, low risk of bias; $H$, high risk of bias; $U$, unclear risk of bias.

parallel design were correlated with its reduction of TC $(\mathrm{WMD}=$ $-21.363 \mathrm{mg} / \mathrm{dl}, 95 \% \mathrm{CI}:-34.090$ to $\left.-8.636, \mathrm{p}=0.001 ; \mathrm{I}^{2}=0.0 \%\right)$, LDL-c (WMD $=-14.434 \mathrm{mg} / \mathrm{dl}, 95 \% \mathrm{CI}:-24.929$ to $-3.939, \mathrm{p}=$ $0.007 ; \mathrm{I}^{2}=55.2 \%$ ), and SBP (WMD = -5.778 $\mathrm{mmHg}, 95 \%$ CI: -10.197 to $\left.-1.360, \mathrm{p}=0.010 ; \mathrm{I}^{2}=28.9 \%\right)$.

\subsection{Sensitivity Analysis and Publication Bias}

There was no significant impact for any individual trial on the pooled effect sizes of meta-analyses results, so the results are reliable.

The funnel plots were asymmetric (Figure 4), indicating a possible publication bias in meta-analysis of the effects of sesamin on hemodynamics. However, the Begg's rank correlation test and Egger's linear regression test suggested no significant publication bias in this meta-analysis (all p $>0.10$ ) (Table 5).

\section{DISCUSSION}

Seven articles with 212 arms were enrolled in our present metaanalysis, which assessed that sesamin supplementation did not affect the levels of HDL-c, TG, DBP, or weight, but with a decrease in TC, LDL-c, and SBP. These changes varied substantially depending on the duration, study design, and health status. In a previous meta-analysis on dietary lignans, sesamin was mentioned, but which was not analyzed alone for an accurate result (31), as we did.

Compared to the current drug therapy, dietary supplements taking sesame for an example may potentially provide a rather safe, healthy, and low-cost way to prevent disease. A previous metaanalysis by Khalesi et al. showed that sesame affected the level of TG markedly (32), and its public health implication is bright. Sesame was widely applied for its heart protection (33) which may be because of its lignans such as sesamin and sesamolin $(34,35)$. Sesamin is composed of carbon, hydrogen, and oxygen, whose molecular formula is $\mathrm{C}_{20} \mathrm{H}_{18} \mathrm{O}_{6}$, and its weight per mole is $354.35 \mathrm{~g}$ (36). Due to its health benefits, more and more animal and human experiments have been conducted in the past two decades.

\subsection{Effects on Obesity}

The rapid increase in obesity rates among adolescents and children around the world has shocked us (37). The status of obesity is not hopeful either, and the rise in adult obesity continues to rise (38). Since the outbreak of COVID-19, the interplay of obesity and COVID-19 has had devastating consequences with increased morbidity and mortality (39).
Neidich et al. demonstrated that obese individuals were twice as likely to get the flu as healthy people who received the same vaccine (40). The health-related burden associated with obesity is estimated to have a substantial economic impact (41). Helli et al. have proved that intake of sesamin had a decrease in body weight $(\mathrm{p}=0.001)(30)$. Sesamin increases lipolytic enzyme activity and decreases the activity of lipogenic enzymes, which also affects as an antagonist to liver X receptor ( $\mathrm{LXR} \alpha)$ and pregnane $\mathrm{X}$ receptor (PXR) ameliorating drug-induced hepatic lipogenesis (42, 43). However, our meta-analysis showed that the supplementation of sesamin had no association with reduction in body weight, so the effect of sesamin on weight could not be fully determined.

\subsection{Effects on Blood Pressure}

In the recent decade, hypertension is widely recognized to sharply increase the incidence of cardiovascular disease, which has dramatically increased the medical expenditure for patients around the world $(44,45)$. Through many in vitro and in vivo experiments, we now know that long-term effective antihypertensive therapy can avert hypertension-related mortality by nearly $50 \%$ (46). However, a systematic review written by Tadesse indicated that $45 \%$ of the subjects did not adhere to their antihypertensive medication, existing a low compliance (47). As dietary therapy becomes more and more accepted, sesamin has a good compliance prospect.

Our study revealed that a 4-week administration of $60 \mathrm{mg}$ sesamin caused a decrease in BP with an average of $3.5 \mathrm{mmHg}$ for SBP and $1.9 \mathrm{mmHg}$ for DBP. Wu et al. proceeded a 4-week administration of sesamin and achieved a good antihypertensive effect that can greatly decrease SBP and DBP in mild-hypertensive participants (15). It was reported that patients with RA who consumed $200 \mathrm{mg} /$ day sesamin showed a lower SBP level, but with no remarkable effect on DBP (30). According to Nakano (48), the mechanism of sesamin against high pressure is improving impaired endothelium-dependent vasodilatory responses. Our meta-analysis which covered both SBP and DBP levels indicated significant hypotensive effects of sesamin supplements, depending on study design, duration of treatment, and participants' health status. Our subgroup analyses indicated the antihypertensive function of sesamin in the experimental design type was parallel. What is more, patients who received shorter than 42 days of sesamin and had an unhealthy status can show more obvious effects. Kong et al. showed that sesamin inhibited the progress of eNOS uncoupling, coupled with the effect on p-eNOS increases NO biosynthesis to relieve hypertension. Sesamin also inhibits 

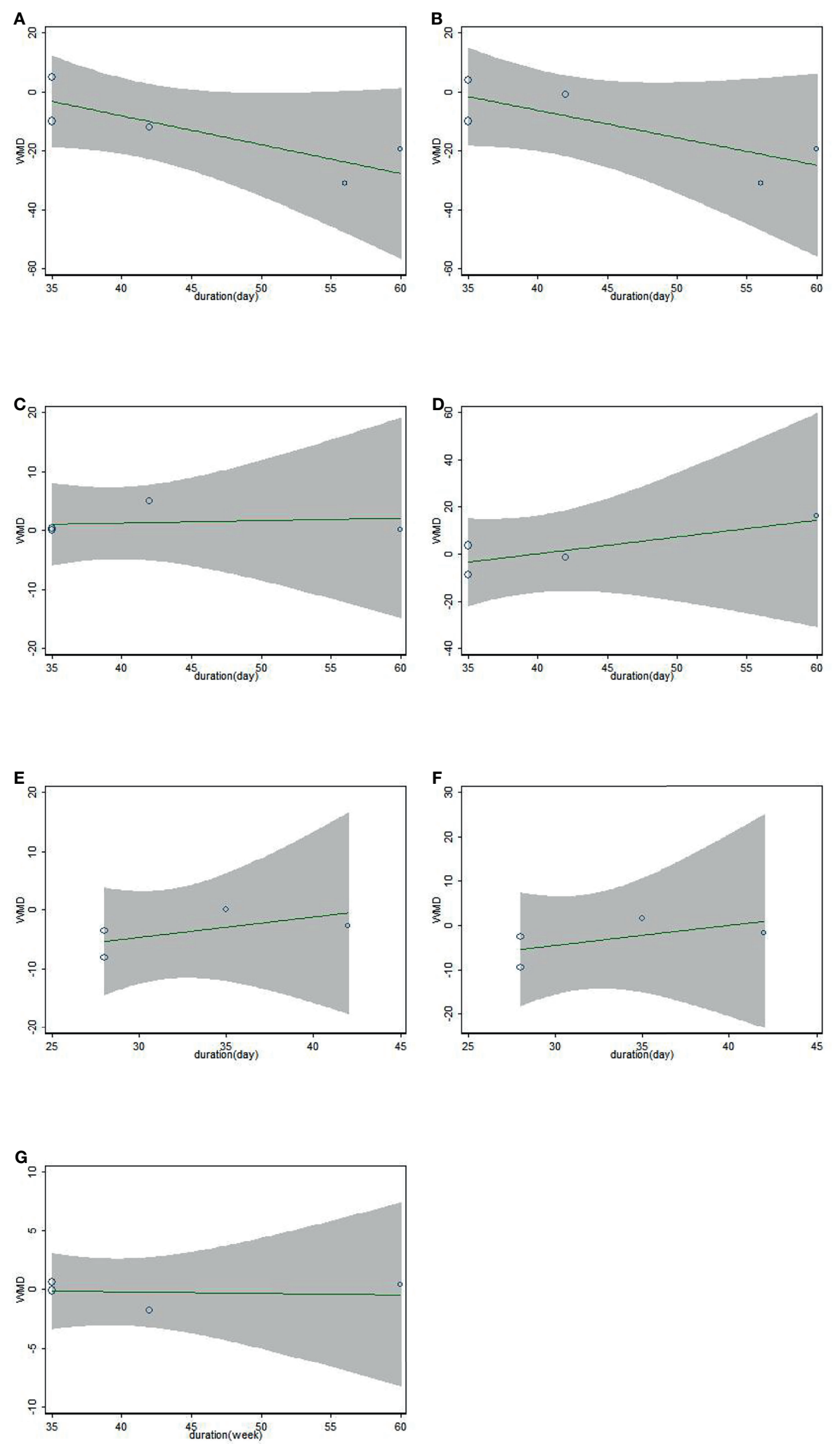

FIGURE 3 | Association between duration of study and effect size of sesamin supplementation on TC (A), LDL-c (B), HDL-c (C), TG (D), SBP (E), DBP (F), and weight (G). 
TABLE 4 | Subgroup analyses.

\begin{tabular}{|c|c|c|c|c|c|c|}
\hline \multirow[t]{2}{*}{ Variables $^{2}$} & \multicolumn{2}{|c|}{ Duration } & \multicolumn{2}{|c|}{ Health status } & \multicolumn{2}{|c|}{ Study design } \\
\hline & $\geq 42$ days & $<42$ days & Healthy & Unhealthy & Parallel & Crossover \\
\hline \multicolumn{7}{|l|}{ TC } \\
\hline No. of treatment arms & 3 & 2 & 2 & 3 & 3 & 2 \\
\hline WMD & -21.363 & -1.082 & -1.082 & -21.363 & -21.363 & -1.082 \\
\hline (95\% Cl) & $(-34.090$ to -8.636$)$ & $(-13.402$ to 11.238$)$ & $(-13.402$ to 11.238$)$ & $(-34.090$ to -8.636$)$ & $(-34.090$ to -8.636$)$ & $(-13.402$ to 11.238$)$ \\
\hline $\mathrm{I}^{2}(\%)$ & 0 & 27.9 & 27.9 & 0 & 0 & 27.9 \\
\hline$P$ & 0.001 & 0.863 & 0.863 & 0.001 & 0.001 & 0.863 \\
\hline \multicolumn{7}{|l|}{$L D L-C$} \\
\hline No. of treatment arms & 3 & 2 & 2 & 3 & 3 & 2 \\
\hline WMD & -14.434 & -1.593 & -1.593 & -14.434 & -14.434 & -1.593 \\
\hline$(95 \% \mathrm{Cl})$ & $(-24.929$ to -3.939$)$ & $\begin{array}{c}(-12.791 \text { to } \\
9.605)\end{array}$ & $(-12.791$ to 9.605$)$ & $(-24.929$ to -3.939$)$ & $(-24.929$ to -3.939$)$ & $(-12.791$ to 9.605$)$ \\
\hline $1^{2}(\%)$ & 55.2 & 29.3 & 29.3 & 55.2 & 55.2 & 29.3 \\
\hline$P$ & 0.007 & 0.780 & 0.780 & 0.007 & 0.007 & 0.780 \\
\hline \multicolumn{7}{|l|}{$H D L-C$} \\
\hline No. of treatment arms & 2 & 2 & 2 & 2 & 2 & 2 \\
\hline WMD & 2.697 & 0.188 & 0.188 & 2.697 & 2.697 & 0.188 \\
\hline (95\% Cl) & $(-1.509$ to 6.902$)$ & $(-4.758$ to 5.135$)$ & $(-4.758$ to 5.135$)$ & (-1.509 to 6.902$)$ & $\begin{array}{c}(-1.509 \text { to } \\
6.902)\end{array}$ & $(-4.758$ to 5.135$)$ \\
\hline $\mathrm{I}^{2}(\%)$ & 21.6 & 0 & 0 & 21.6 & 21.6 & 0 \\
\hline$P$ & 0.209 & 0.941 & 0.941 & 0.209 & 0.209 & 0.941 \\
\hline \multicolumn{7}{|l|}{$T G$} \\
\hline No. of treatment arms & 2 & 2 & 2 & 2 & 2 & 2 \\
\hline WMD & 8.129 & -3.989 & -3.989 & 8.129 & 8.129 & -3.989 \\
\hline (95\% Cl) & $(-27.385$ to 43.644$)$ & $(-19.564$ to 11.586$)$ & $(-19.564$ to 11.586$)$ & (-27.385 to 43.644$)$ & $(-27.385$ to 43.644$)$ & $(-19.564$ to 11.586$)$ \\
\hline $\mathrm{I}^{2}(\%)$ & 0 & 0 & 0 & 0 & 0 & 0 \\
\hline$P$ & 0.654 & 0.616 & 0.616 & 0.654 & 0.654 & 0.616 \\
\hline \multicolumn{7}{|l|}{$S B P$} \\
\hline No. of treatment arms & 1 & 3 & 1 & 3 & 2 & 2 \\
\hline WMD & -2.700 & -3.824 & 0.100 & -4.490 & -5.778 & -2.597 \\
\hline$(95 \% \mathrm{Cl})$ & $(-9.438$ to 4.038$)$ & $(-6.588$ to -1.060$)$ & $(-5.922$ to 6.122$)$ & $(-7.315$ to -1.666$)$ & $(-10.197$ to -1.360$)$ & $(-5.733$ to 0.539$)$ \\
\hline $1^{2}(\%)$ & 0 & 45.9 & 0 & 0 & 28.9 & 5.4 \\
\hline$P$ & 0.432 & 0.007 & 0.974 & 0.002 & 0.010 & 0.105 \\
\hline \multicolumn{7}{|l|}{$D B P$} \\
\hline No. of treatment arms & 1 & 3 & 1 & 3 & 2 & 2 \\
\hline WMD & -1.800 & -2.695 & 1.500 & -3.542 & -5.174 & -0.832 \\
\hline (95\% Cl) & (-6.348 to 2.748$)$ & $(-7.303$ to 1.912$)$ & $(-2.283$ to 5.283$)$ & $(-6.873$ to -0.210$)$ & $(-12.662$ to 2.314$)$ & (-4.811 to 3.148$)$ \\
\hline $\mathrm{I}^{2}(\%)$ & 0 & 74.9 & 0 & 46.0 & 69.5 & 69.4 \\
\hline$P$ & 0.438 & 0.252 & 0.437 & 0.037 & 0.176 & 0.682 \\
\hline \multicolumn{7}{|l|}{ WEIGHT } \\
\hline No. of treatment arms & 2 & 2 & 2 & 2 & 2 & 2 \\
\hline WMD & -0.762 & 0.087 & 0.087 & -0.762 & -0.762 & 0.087 \\
\hline (95\% Cl) & $(-6.630$ to 5.106$)$ & $(-4.359$ to 4.532$)$ & $(-4.359$ to 4.532$)$ & $(-6.630$ to 5.106$)$ & $(-6.630$ to 5.106$)$ & (-4.359 to 4.532$)$ \\
\hline $\mathrm{I}^{2}(\%)$ & 0 & 0 & 0 & 0 & 0 & 0 \\
\hline P & 0.799 & 0.969 & 0.969 & 0.799 & 0.799 & 0.969 \\
\hline
\end{tabular}

TC, total cholesterol; LDL-C, low-density lipoprotein cholesterol; HDL-c, high-density lipoprotein cholesterol; TG, triglycerides; SBP, systolic blood pressure; DBP, diastolic blood pressure; $W M D$, weighed mean difference; $C l$, confidence intervals.

$\mathrm{mg} / \mathrm{dl}$ for TC, LDL-C, HDL-C, TG; $\mathrm{mmHg}$ for SBP and DBP.

2 is inherent to 12 .

NADPH oxidase contributing to the suppression of hypertension in hypertensive rats (49).

\subsection{Effects on Lipid Profiles}

Hyperlipidemia, a life-threatening health condition endangering the life of most patients (50), represents as increasing TC/TG/LDL$c$ or decreasing HDL-c (51). With elevated LDL-c concentration as a risk factor, statins can effectively reduce the concentration to play an anti-hyperlipidemia role $(52,53)$. Although statins' primary application is to lower cholesterol (54), drug toxicity to the human body is still unavoidable. "Pharmacograde nutrients" may be a potentially safe, healthy, and cheap way to optimize lipid levels (55). Hirata et al. suggested that sesamin together with vitamin $\mathrm{E}$ can reduce the LDL-c level effectively $(\mathrm{p}<0.05)(21)$. Another research conducted by Mohammadshahi (22) declared that by supplementing a daily dose of $200 \mathrm{mg}$ sesamin to patients with Type II diabetes, the level of TG, TC, and LDL-c became reduced. There is a biological basis of lipid lowering; Tai et al. (43)showed that sesamin might improve blood lipid by reducing hepatic steatosis and absorption of cholesterol through the intestine. Majdalawieh et al. (36) revealed that sesamin mainly played anti-hyperlipidemic roles by aiming at $\Delta 5$ desaturase, HMGCR, 
A

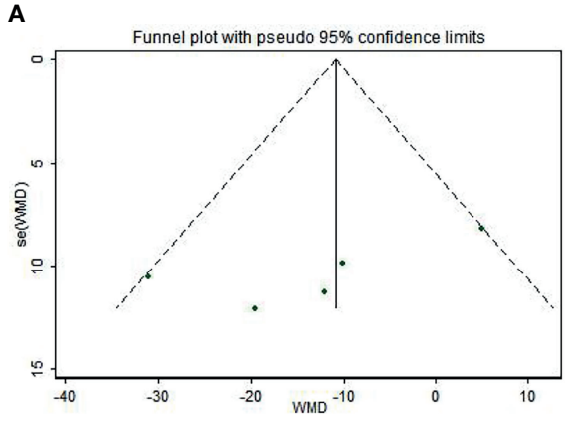

C

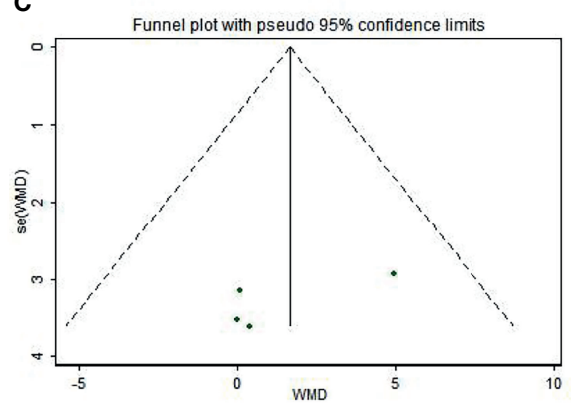

E

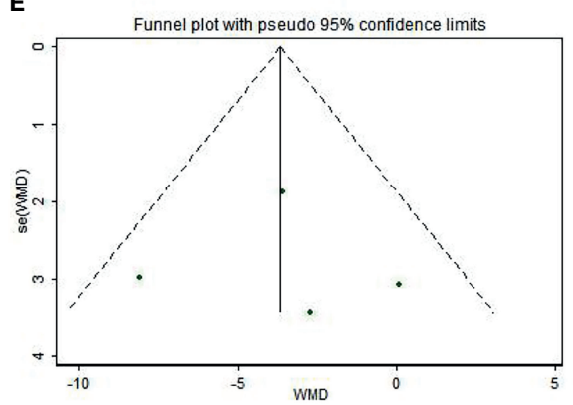

B

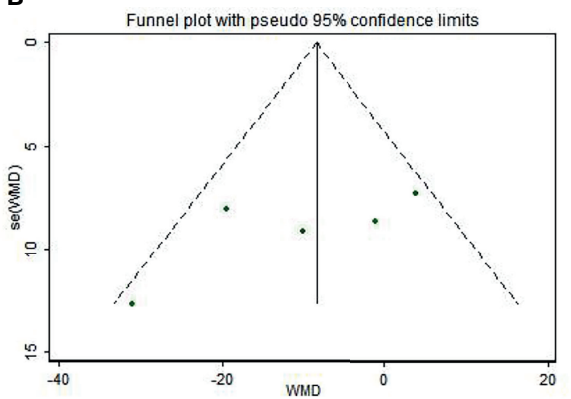

D

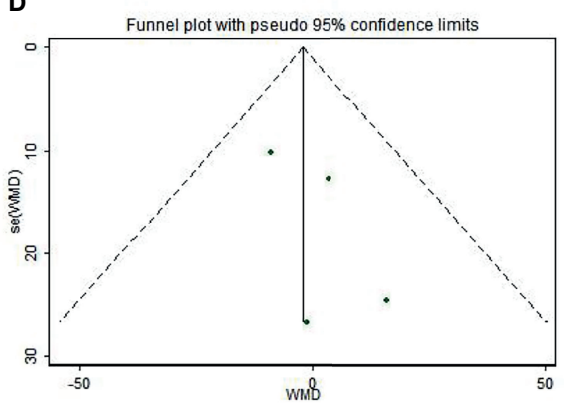

G
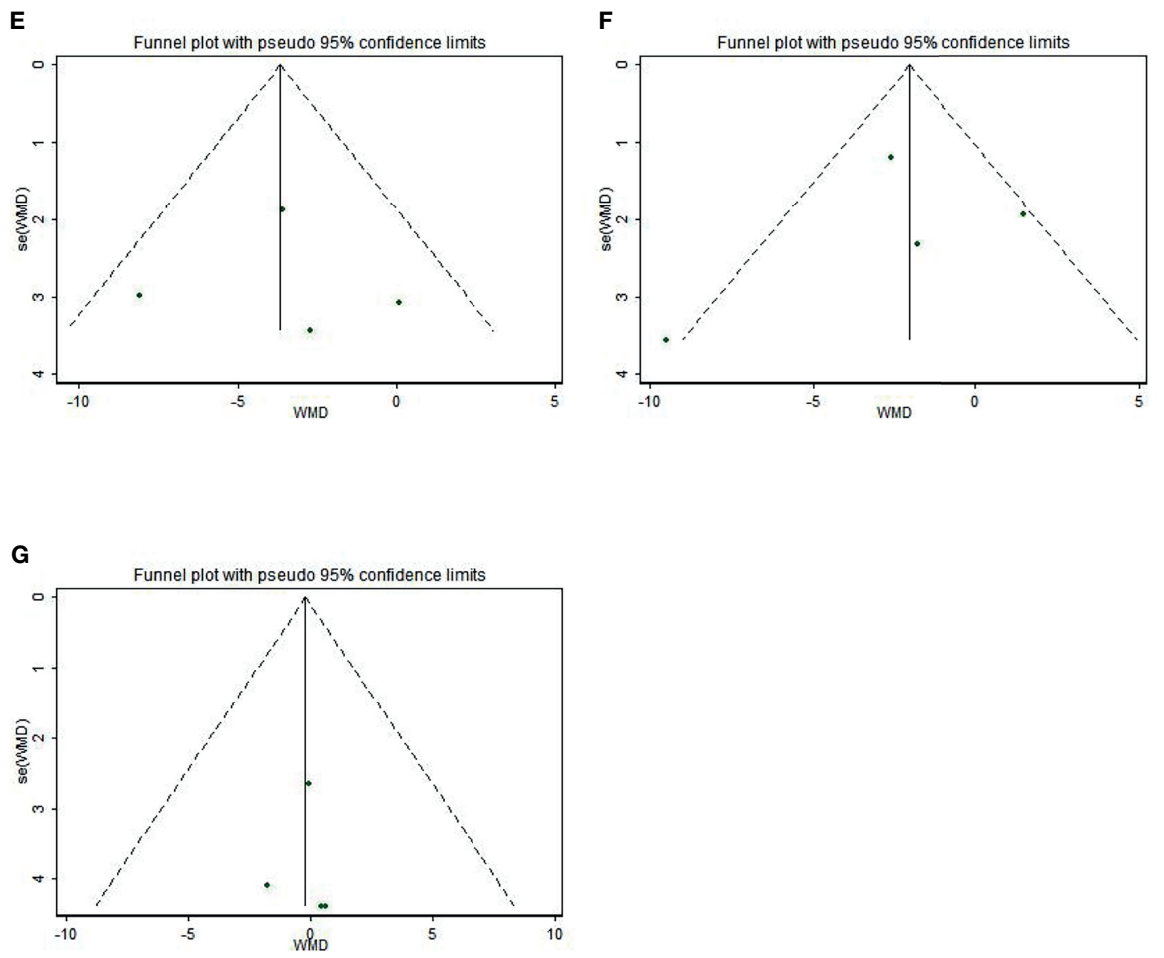

FIGURE 4 | Funnel plot of the effect of sesamin supplementation on TC (A), LDL-c (B), HDL-c (C), TG (D), SBP (E), DBP (F), and weight (G) 
TABLE 5 | Assessment of publication bias.

\begin{tabular}{|c|c|c|c|c|c|c|}
\hline & \multicolumn{3}{|c|}{ Begg's rank correlation test } & \multicolumn{3}{|c|}{ Egger's linear regression test } \\
\hline & Kendal's score & $Z$ value & $P$ value & Intercept & $95 \% \mathrm{Cl}$ & $P$ value \\
\hline TC & -6 & -1.47 & 0.142 & -7.052 & $(-17.595,3.490)$ & 0.123 \\
\hline LDL & -6 & -1.47 & 0.142 & -5.415 & $(-15.558,4.728)$ & 0.188 \\
\hline $\mathrm{HDL}$ & 0 & 0 & 1.000 & -6.138 & $(-21.603,9.327)$ & 0.230 \\
\hline TG & 2 & 0.68 & 0.497 & 0.956 & $(-2.388,4.299)$ & 0.344 \\
\hline SBP & 2 & 0.68 & 0.497 & 0.209 & $(-11.693,12.111)$ & 0.947 \\
\hline DBP & -2 & -0.68 & 0.497 & -1.192 & $(-12.279,9.895)$ & 0.689 \\
\hline Weight & 4 & 1.36 & 0.174 & -0.013 & $(-3.065,3.039)$ & 0.987 \\
\hline
\end{tabular}

ABCA1, and ABCG1 through PPAR $\alpha$, PPAR $\gamma, \mathrm{LXR} \alpha$, and SREBP signaling pathways, which is important for the future supplement of sesamin.

Our meta-analysis showed that daily intake of sesamin was effective in improving LDL-c and TC levels but had no significant influence on TG and HDL-c. Long-term ( $\geq 42$ days) sesamin intake is more effective than a short period of supplement. The reason may be that sesamin, as a food of nutrition, can make its accumulation in the body more obvious after long-term ingestion. The meta-regression showed LDL-c's trend becoming flat over time. Perhaps this is because LDL-c fluctuates in a dynamic range for different individuals, flattening out as its concentration nears a critical level. In the experiment conducted by $\mathrm{Wu}$ et al. (23), the duration was so short that sesamin played no role. Therefore, no significant influence on the indexes of lipid profile was indicated. Probably due to one crossover RCT with short-term included, findings also indicated that TC and LDL-c levels were decreased when the RCT was designed to be parallel-controlled.

Integrated data from numerous selected studies are the major superiority of our study, so the reliability and accuracy of our analysis are robust. The seven indicators we included were carefully selected and of great clinical guiding significance. What is more, the studies we included from various geographic regions around the world, so our conclusion has a wide range of application value for people in different cultural backgrounds. Additionally, our review not only provides a new food therapy target for people who are in an unhealthy status but also facilitates guidance for the development of dietary intervention therapy in the future.

The limitations of our study were self-explanatory. Firstly, a relatively small sample size of the included studies may cause a higher risk for publication bias whereas Begg's and Egger's tests suggested no significant publication bias in our meta-analyses. Secondly, the heterogeneity of LDL-c was relatively high, but we found that this may be caused by long duration, unhealthy status, or parallel-design trials. Thirdly, the gender ratio in the studies we included was different, and the influence of hormone level on obesity, lipid profile, and blood pressure could not be ignored.

\section{CONCLUSION}

Taken together, our results indicate that sesamin can be used as an easily obtainable dietary supplement to improve BP and blood lipids, and further as a health product to prevent cardiovascular diseases. In the future, large multinational prospective randomized controlled trials should help determine the ideal dose, duration, and formulation of the sesamin intervention specific to each individual patient's health status. More multi-geographical trials with sufficient subjects, involving more countries, hoped to be conducted for the ideal dose, for the appropriate duration, and for individual patients' fitting target.

In terms of implications for practice, the evidence from our meta-analysis suggests that unhealthy subjects taking sesamin may improve the lipid profile and BP more remarkably.

\section{DATA AVAILABILITY STATEMENT}

The original contributions presented in the study are included in the article/Supplementary Material. Further inquiries can be directed to the corresponding author.

\section{AUTHOR CONTRIBUTIONS}

Substantial contributions to the conception and design of the meta-analysis were done by JYR and YXM. The literature search and data extraction were done by YTS, JYR, and SQZ. The data analyses were done by ZAZ, ZHG, JQA, and BWY. The manuscript and revision were done by YTS, JYR, and YXM. All authors contributed to the article and approved the submitted version.

\section{FUNDING}

This study was supported by the National Natural Science Foundation of China [No. 81874264].

\section{SUPPLEMENTARY MATERIAL}

The Supplementary Material for this article can be found online at: https://www.frontiersin.org/articles/10.3389/fendo.2022.842152/ full\#supplementary-material 


\section{REFERENCES}

1. Thomas H, Diamond J, Vieco A, Chaudhuri S, Shinnar E, Cromer S, et al. Global Atlas of Cardiovascular Disease 2000-2016: The Path to Prevention and Control. Glob Heart (2018) 13:143-63. doi: 10.1016/j.gheart.2018.09.511

2. Piepoli MF, Hoes AW, Agewall S, Albus C, Brotons C, Catapano AL, et al. [2016 European Guidelines on Cardiovascular Disease Prevention in Clinical Practice. The Sixth Joint Task Force of the European Society of Cardiology and Other Societies on Cardiovascular Disease Prevention in Clinical Practice (Constituted by Representatives of 10 Societies and by Invited Experts. Developed With the Special Contribution of the European Association for Cardiovascular Prevention \& Rehabilitation]. Giornale Italiano di Cardiologia (2016) 547-612. doi: 10.1177/2047487316653709

3. Yusuf S, Hawken S, Ounpuu S, Dans T, Avezum A, Lanas F, et al. Effect of Potentially Modifiable Risk Factors Associated With Myocardial Infarction in 52 Countries (the INTERHEART Study): Case-Control Study. Lancet (London England) (2004) 364:937-52. doi: 10.1016/S0140-6736(04) 17018-9

4. Hong KN, Fuster V, Rosenson RS, Rosendorff C, Bhatt DL. How Low to Go With Glucose, Cholesterol, and Blood Pressure in Primary Prevention of CVD. J Am Coll Cardiol (2017) 70:2171-85. doi: 10.1016/j.jacc.2017.09.001

5. Chait A, Eckel RH. Lipids, Lipoproteins, and Cardiovascular Disease: Clinical Pharmacology Now and in the Future. J Clin Endocrinol Metab (2016) 101:804-14. doi: 10.1210/jc.2015-3940

6. Stokes KY, Cooper D, Tailor A, Granger DN. Hypercholesterolemia Promotes Inflammation and Microvascular Dysfunction: Role of Nitric Oxide and Superoxide. Free Radical Biol Med (2002) 33:1026-36. doi: 10.1016/S08915849(02)01015-8

7. Stapleton PA, Goodwill AG, James ME, Brock RW, Frisbee JC. Hypercholesterolemia and Microvascular Dysfunction: Interventional Strategies. J Inflamm (London England) (2010) 7:54. doi: 10.1186/14769255-7-54

8. Scicali R, Di Pino A, Ferrara V, Urbano F, Piro S, Rabuazzo AM, et al. New Treatment Options for Lipid-Lowering Therapy in Subjects With Type 2 Diabetes. Acta Diabetologica (2018) 55:209-18. doi: 10.1007/s00592-0171089-4

9. Chapman MJ. Metabolic Syndrome and Type 2 Diabetes: Lipid and Physiological Consequences. Diabetes Vasc Dis Res (2007) 4 Suppl 3:S5-8. doi: $10.3132 /$ dvdr.2007.050

10. Musunuru K. Atherogenic Dyslipidemia: Cardiovascular Risk and Dietary Intervention. Lipids (2010) 45:907-14. doi: 10.1007/s11745-010-3408-1

11. Assmann G. Dyslipidaemia and Global Cardiovascular Risk: Clinical Issues. Eur Heart J Suppl (2006) 8:F40-6. doi: 10.1093/eurheartj/sul040

12. Nishtar S. NCD Risk Factor Collaboration (NCD-Risc). Lancet (2017) 389 (10064):37-55. doi: 10.1016/S0140-6736(16)31919-5

13. Chen PR, Chien KL, Su TC, Chang CJ, Liu T-L, Cheng H, et al. Dietary Sesame Reduces Serum Cholesterol and Enhances Antioxidant Capacity in Hypercholesterolemia. Nutr Res (2005) 25:559-67. doi: 10.1016/j.nutres. 2005.05.007

14. Dar AA, Arumugam N. Lignans of Sesame: Purification Methods, Biological Activities and Biosynthesis-A Review. Bioorganic Chem (2013) 50:1-10. doi: 10.1016/j.bioorg.2013.06.009

15. Miyawaki T, Aono H, Toyoda-Ono Y, Maeda H, Kiso Y, Moriyama K. Antihypertensive Effects of Sesamin in Humans. J Nutr Sci Vitaminology (2009) 55:87-91. doi: 10.3177/jnsv.55.87

16. Rogi T, Tomimori N, Ono Y, Kiso Y. The Mechanism Underlying the Synergetic Hypocholesterolemic Effect of Sesamin and $\alpha$-Tocopherol in Rats Fed a High-Cholesterol Diet. J Pharmacol Sci (2011) 115(3):408-16. doi: 10.1254/jphs.10287fp

17. Yuliana ND, Iqbal M, Jahangir M, Wijaya CH, Korthout $\mathrm{H}$, Kottenhage $\mathrm{M}$, et al. Screening of Selected Asian Spices for Anti Obesity-Related Bioactivities. Food Chem (2011) 126:1724-9. doi: 10.1016/j.foodchem.2010.12.066

18. Yang JR. Therapeutics, Effects of Sesamin on Blood Glucose,Blood Lipids and Vascular Cell Adhesion Molecule-1 Protein Expression of Aorta in Rats With Metabolic Syndrome. Chin J Clin Pharmacol Ther (2008) 13(2):195.

19. Sirato-Yasumoto S, Katsuta M, Okuyama Y, Takahashi Y, Ide T. Effect of Sesame Seeds Rich in Sesamin and Sesamolin on Fatty Acid Oxidation in Rat Liver. J Agric Food Chem (2001) 49:2647-51. doi: 10.1021/jf001362t
20. Ashakumary L, Rouyer I, Takahashi Y, Ide T, Sugano MJM. Sesamin, a Sesame Lignan, Is a Potent Inducer of Hepatic Fatty Acid Oxidation in the Rat. Metabolism (1999) 48:1303-13. doi: 10.1016/S0026-0495(99)90272-X

21. Hirata F, Fujita K, Ishikura Y, Hosoda K, Ishikawa T, Nakamura H. Hypocholesterolemic Effect of Sesame Lignan in Humans. Atherosclerosis (1996) 122:135-6. doi: 10.1016/0021-9150(95)05769-2

22. Mohammadshahi M, Zakerzadeh M, Zakerkish M, Zarei M, Saki A. Effects of Sesamin on the Glycemic Index, Lipid Profile, and Serum Malondialdehyde Level of Patients With Type II Diabetes. J Babol Univ Med Sci (2016) 18:7-14. doi: $10.22088 /$ jbums.18.6.7

23. Wu JH, Hodgson JM, Puddey IB, Belski R, Burke V, Croft KD. Sesame Supplementation Does Not Improve Cardiovascular Disease Risk Markers in Overweight Men and Women. Nutr Metab Cardiovasc Dis NMCD (2009) 19:774-80. doi: 10.1016/j.numecd.2009.01.003

24. Wichitsranoi J, Weerapreeyakul N, Boonsiri P, Settasatian C, Settasatian N, Komanasin N, et al. Antihypertensive and Antioxidant Effects of Dietary Black Sesame Meal in Pre-Hypertensive Humans. Nutr J (2011) 10:82. doi: 10.1186/1475-2891-10-82

25. Page MJ, Moher D, Bossuyt PM, Boutron I, Hoffmann TC, Mulrow CD, et al PRISMA 2020 Explanation and Elaboration: Updated Guidance and Exemplars for Reporting Systematic Reviews. BMJ (2021) 372:n160. doi: 10.1136/bmj.n160

26. Higgins JP, Altman DG, Gotzsche PC, Juni P, Moher D, Oxman AD, et al. The Cochrane Collaboration's Tool for Assessing Risk of Bias in Randomised Trials. BMJ (2011) 343:d5928. doi: 10.1136/bmj.d5928

27. Begg CB, Mazumdar M. An Adjusted Rank Correlation Test Is Proposed as a Technique for Identifying Publication Bias in a Meta-Analysis, and Its Operating Characteristics Are Evaluate. Biometrics (1994) 50(4):1088-101. doi: $10.2307 / 2533446$

28. Egger M, Davey Smith G, Schneider M, Minder C. Bias in Meta-Analysis Detected by a Simple, Graphical Test. BMJ (1997) 315:629-34. doi: 10.1136/ bmj.315.7109.629

29. Wu WH, Kang YP, Wang NH, Jou HJ, Wang TA. Sesame Ingestion Affects Sex Hormones, Antioxidant Status, and Blood Lipids in Postmenopausal Women. J Nutr (2006) 136:1270-5. doi: 10.1093/jn/136.5.1270

30. Helli B, Mowla K, Mohammadshahi M, Jalali MT. Effect of Sesamin Supplementation on Cardiovascular Risk Factors in Women With Rheumatoid Arthritis. J Am Coll Nutr (2016) 35:300-7. doi: 10.1080/ 07315724.2015.1005198

31. Peterson J, Dwyer J, Adlercreutz H, Scalbert A, Jacques P, McCullough ML. Dietary Lignans: Physiology and Potential for Cardiovascular Disease Risk Reduction. Nutr Rev (2010) 68:571-603. doi: 10.1111/j.1753-4887.2010. 00319.x

32. Khalesi S, Paukste E, Nikbakht E, Khosravi-Boroujeni H. Sesame Fractions and Lipid Profiles: A Systematic Review and Meta-Analysis of Controlled Trials. Br J Nutr (2016) 115:764-73. doi: 10.1017/S0007114515005012

33. Cheng FC, Jinn TR, Hou RC, Tzen JT. Neuroprotective Effects of Sesamin and Sesamolin on Gerbil Brain in Cerebral Ischemia. Int J BioMed Sci (2006) 2:284-8.

34. Sankar D, Rao MR, Sambandam G, Pugalendi KV. Effect of Sesame Oil on Diuretics or Beta-Blockers in the Modulation of Blood Pressure, Anthropometry, Lipid Profile, and Redox Status. Yale J Biol Med (2006) 79:19-26.

35. Namiki M. Nutraceutical Functions of Sesame: A Review. Crit Rev Food Sci Nutr (2007) 47:651-73. doi: 10.1080/10408390600919114

36. Majdalawieh AF, Dalibalta S, Yousef SM. Effects of Sesamin on Fatty Acid and Cholesterol Metabolism, Macrophage Cholesterol Homeostasis and Serum Lipid Profile: A Comprehensive Review. Eur J Pharmacol (2020) 885:173417. doi: 10.1016/j.ejphar.2020.173417

37. Ogden CL, Carroll M, Lawman HG, Fryar CD, Kruszon-Moran D, Kit BK, et al. Trends in Obesity Prevalence Among Children and Adolescents in the United States, 1988-1994 Through 2013-2014. JAMA (2016) 315:2292-9. doi: 10.1001/jama.2016.6361

38. Ng M, Fleming T, Robinson M, Thomson B, Graetz M, Margono C. Global, Regional, and National Prevalence of Overweight and Obesity in Children and Adults During 1980-2013: A Systematic Analysis for the Global Burden of Disease Study 2013. J Lancet (2014) 384:766-81. doi: 10.1016/S0140-6736(14) 60460-8 
39. Browne NT, Snethen JA, Greenberg CS, Frenn M, Lewandowski L. When Pandemics Collide: The Impact of COVID-19 on Childhood Obesity. J Pediatr Nurs (2020) 56:90-8. doi: 10.1016/j.pedn.2020.11.004

40. Neidich SD, Green WD, Rebeles J, Karlsson EA, Schultz-Cherry S, Noah TL, et al. Increased Risk of Influenza Among Vaccinated Adults Who Are Obese. Int J Obes (2017) 2005) 41:1324-30. doi: 10.1038/ijo.2017.131

41. Wang YC, McPherson K, Marsh T, Gortmaker SL, Brown M. Health and Economic Burden of the Projected Obesity Trends in the USA and the UK. Lancet (London England) (2011) 378:815-25. doi: 10.1016/S0140-6736(11)60814-3

42. Ide T, Ashakumary L, Takahashi Y, Kushiro M, Fukuda N, Sugano M. Sesamin, a Sesame Lignan, Decreases Fatty Acid Synthesis in Rat Liver Accompanying the Down-Regulation of Sterol Regulatory Element Binding Protein-1. Biochim Biophys Acta (2001) 1534:1-13. doi: 10.1016/S1388-1981 (01)00167-6

43. Tai TS, Tien N, Shen HY, Chu FY, Wang CCN, Lu CH, et al. Sesamin, a Naturally Occurring Lignan, Inhibits Ligand-Induced Lipogenesis Through Interaction With Liver X Receptor Alpha (LXR $\alpha$ ) and Pregnane X Receptor (PXR). Evid Based Complement Alternat Med (2019) 2019:1-17. doi: 10.1155/ 2019/9401648

44. Kishore SP, Heller DJ, Vasan A. Beyond Hypertension: Integrated Cardiovascular Care as a Path to Comprehensive Primary Care. Bull World Health Organ (2018) 96:219-21. doi: 10.2471/BLT.17.197996

45. Tam HL, Wong EML, Cheung K, Chung SF. Effectiveness of Text Messaging Interventions on Blood Pressure Control Among Patients With Hypertension: Systematic Review of Randomized Controlled Trials. JMIR mHealth $u$ Health (2021) 9:e24527. doi: 10.2196/24527

46. Heller DJ, Kishore SP. Closing the Blood Pressure Gap: An Affordable Proposal to Save Lives Worldwide. BMJ Glob Health (2017) 2:e000429. doi: 10.1136/bmigh-2017-000429

47. Abegaz TM, Shehab A, Gebreyohannes EA, Bhagavathula AS, Elnour AA. Nonadherence to Antihypertensive Drugs: A Systematic Review and MetaAnalysis. Med (Baltimore) (2017) 96:e5641. doi: 10.1097/MD.0000000000005641

48. Nakano D, Itoh C, Takaoka M, Kiso Y, Tanaka T, Matsumura Y. Antihypertensive Effect of Sesamin. IV. Inhibition of Vascular Superoxide Production by Sesamin. Biol Pharm Bull (2002) 25:1247-9. doi: 10.1248/ bpb.25.1247

49. Kong X, Li W, Guo LQ, Zhang JX, Chen XP, Liu WY, et al. Sesamin Enhances Nitric Oxide Bioactivity in Aortas of Spontaneously Hypertensive Rats. Ther Adv Cardiovasc Dis (2015) 9:314-24. doi: 10.1177/1753944715586178
50. Ezeh KJ, Ezeudemba O. Hyperlipidemia: A Review of the Novel Methods for the Management of Lipids. Cureus (2021) 13:e16412. doi: 10.7759/ cureus.16412

51. Peng Q, Yao X, Xiang J, Wang Y, Lin X. Acupuncture for Hyperlipidemia: Protocol for a Systematic Review and Meta-Analysis. Med (Baltimore) (2018) 97:e13041. doi: 10.1097/MD.0000000000013041

52. Grundy SM, Cleeman JI, Merz C, Brewer HB, Stone NJ. Implications of Recent Clinical Trials for the National Cholesterol Education Program Adult Treatment Panel III Guidelines. Arterioscler Thromb Vasc Biol (2004) 44:1329-30. doi: 10.1161/01.ATV.0000139012.45265.e0

53. Expert Panel on Detection, Evaluation, and Treatment of High Blood Cholesterol in Adults. Circulation, Executive Summary of the Third Report of the National Cholesterol Education Program (NCEP) Expert Panel on Detection, Evaluation, and Treatment of High Blood Cholesterol in Adults (Adult Treatment Panel III). JAMA (2001) 106:3143-421. doi: 10.1001/ jama.285.19.2486

54. Tobert JA. Lovastatin and Beyond: The History of the HMG-Coa Reductase Inhibitors. Nat Rev Drug Discov (2003) 2:517-26. doi: 10.1038/nrd1112

55. Rivellese AA, Ciciola P, Costabile G, Vetrani C, Vitale M. The Possible Role of Nutraceuticals in the Prevention of Cardiovascular Disease. High Blood Press Cardiovasc Prev (2019) 26(2):101-11. doi: 10.1007/s40292-019-00309-5

Conflict of Interest: The authors declare that the research was conducted in the absence of any commercial or financial relationships that could be construed as a potential conflict of interest.

Publisher's Note: All claims expressed in this article are solely those of the authors and do not necessarily represent those of their affiliated organizations, or those of the publisher, the editors and the reviewers. Any product that may be evaluated in this article, or claim that may be made by its manufacturer, is not guaranteed or endorsed by the publisher.

Copyright (c) 2022 Sun, Ren, Zhu, Zhang, Guo, An, Yin and Ma. This is an openaccess article distributed under the terms of the Creative Commons Attribution License (CC BY). The use, distribution or reproduction in other forums is permitted, provided the original author(s) and the copyright owner(s) are credited and that the original publication in this journal is cited, in accordance with accepted academic practice. No use, distribution or reproduction is permitted which does not comply with these terms. 